This is a postprint version of the following published document:

González-Benito, J., Baselga, J. \& Aznar, A.

(1999). Microstructural and wettability study of

surface pretreated glass fibres. Journal of

Materials Processing Technology, 92-93, pp.

129-134.

DOI: $10.1016 / \mathrm{S} 0924-0136(99) 00212-5$

(C) Elsevier, 1999

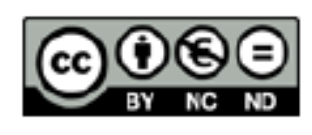

This work is licensed under a Creative Commons Attribution-NonCommercialNoDerivatives 4.0 International License. 


\title{
Microstructural and wettability study of surface pretreated glass fibres
}

\author{
J. González-Benito, J. Baselga, A.J. Aznar ${ }^{*}$ \\ Universidad Carlos III de Madrid, Departamento de Ingeniería, C/Butarque 15, E-289, Leganés, Spain
}

Commercial glass fibres were calcinated for the removal of organic matter, activated for surface silanol regeneration and silanizated with $\gamma$-aminopropyltri-ethoxysilane. Two different activation methods were used: reflux with neutral water and reflux with $10 \% \mathrm{HCl}$ aqueous solution. Acid treatments hydrolize $\mathrm{Si}-\mathrm{O}$ bonds, greatly changing the composition of the glass and regenerating silanol groups, some of them being of intraglobular nature. Water treatment does not change appreciably the

glass composition, but its surface free energy value is the lowest. The degree of silanization is the greatest for the acid activated samples and the lowest for the water activated one. The polar contribution to the total surface free energy, once the samples are silanizated, is the highest for the fibres activated with boiling water whilst the dispersion component is about the same for all of them. SEM observations indicate that for the greatest degree of coating, debonding of the filaments may induce a peeling-out fractural mechanism.

Glass fibres; Surface tension; APES

\section{Introduction}

It is well known that to improve the properties of glass fibre reinforced polymer matrix composites it is necessary to form high-strength, chemically-stable interfaces between the reinforcement and the matrix. Surface treatments of fibres are usually carried out by reacting surface silanol groups with silane coupling agents [1-3].

Up to now the research in this field has been focused mainly on the characterisation of the substrate surface (acidbase properties and quantification of the number and distribution of surface silanol groups [1,4-6]) and on the characterisation of the silane coupling agent coating-structure of the polyorganosiloxane layer [7-14] and orientation of the silane organo-functional groups. To the best of the authors' knowledge, no work has been undertaken on the effects of surface treatments, prior to the silanization, on the structure and properties of the silane coupling agent layer.

There are many different methods for the surface characterisation of silane-treated glass fibres as well as for the interfaces with the polymer matrix [15]. Fourier transform infrared spectrometry (FTIR) is a particularly useful tech-

*Corresponding author. Tel.: 34-916249466; fax: 34-916249430

E-mail address: aaznar@ing.uc3m.es (A.J. Aznar) nique to study silane coupling agents adsorbed or bounded to glass surfaces $[8-10,16]$. However, the very small amount of coupling agent normally applied to the glass surface and the presence of strong bands from the substrate, often makes the IR detection of the silane characteristic bands difficult.

The measurement of dynamic contact angles (advancing and receeding) and contact angle hysteresis is a complementary mean for macroscopic characterisation of coupling agent modified surfaces, allowing the surface free energy to be calculated, and the orientation of the organo-functional groups $[7,12]$ to be estimated.

In this work the influence of different activation pretreatments of glass fibres on the structure of an aminosilane ( $\gamma$-aminopropyltriethoxysilane) coupling agent layer is studied making use of SEM, FTIR and dynamic contact angle measurements.

\section{Experimental part}

The glass fibre was supplied by Vetrotex (Spain) and was calcinated at $450^{\circ} \mathrm{C}$ for $1 \mathrm{~h}$ for removing organic matter, prior to use. All reactives were of reactive grade.

The fibres were subjected to two different activation processes: treatment with boiling water and reflux with 
Table 1

Sample codes and activation procedures

\begin{tabular}{lll}
\hline Sample & Activation reagent & Activation time (h) \\
\hline F-A & None & None \\
F-B & Water & 1 \\
F-C & HCl $10 \%$ & 1 \\
F-D & & 3 \\
\hline
\end{tabular}

$10 \% \mathrm{HCl}$ aqueous solution. The activation times and samples codes are summarised in Table 1. After acid activation, all of the samples were washed repeatedly with distilled water until $\mathrm{Cl}$ removal. All the samples were dried at $110^{\circ} \mathrm{C}$ for $1 \mathrm{~h}$ and kept in a dessicator until silanization.

Silanization of activated fibres was performed using a $1 \%$ (v/v) $\gamma$-aminopropyltri-ethoxysilane (APES) aqueous solution for $10 \mathrm{~min}$. Polymerisation of silanizated fibres was performed at $110^{\circ} \mathrm{C}$ for $1 \mathrm{~h}$ in an oven and afterwards they were subjected to Soxhlet extraction with dried toluene for $16 \mathrm{~h}$ and vacuum dried for $12 \mathrm{~h}$. The silanizated samples were stored in a dessicator until use. The codes for silanizated samples are the same as for activated, but with the addition of an $\mathrm{S}(\mathrm{F}-\mathrm{x}-\mathrm{S})$.

Microscopic examination and semiquantitative X-ray microanalysis were performed using a Philips XL30 scanning electron microscope (SEM) with an EDAX detector DX4i, on both activated and silanizated samples (Au/Pt coated). Chemical analysis data are expressed as the average of four different measurements on different fibre samples.

Transmission Fourier transform infrared spectra were performed on a Mattson Galaxy 3000 instrument (4000$400 \mathrm{~cm}^{-1}$ range, 100 scans, $4 \mathrm{~cm}^{-1}$ resolution): the fibres were ground, diluted up to $3 \%$ with $\mathrm{KBr}$ and press moulded in an evacuated press at $9 \mathrm{~atm}$ to form disks of $12 \mathrm{~mm}$. diameter.

Dynamic wettability was measured using a Krüss K14 dynamic contact angle analyser. A single glass fibre was fixed to the electrobalance by means of adhesive tape and the force on the fibre was measured as the liquid container was raised and withdrawn at a stage velocity of $50 \mu \mathrm{m} \mathrm{s}^{-1}$. The liquids were water, ethylenglycol and $\alpha$-bromonaphtalene at $24^{\circ} \mathrm{C}$. The fibre perimeter was measured for each fibre with an optical microscope immediately before each wettability measurement. The cosines of the advancing contact angles were calculated by the wetting force extrapolated to zero depth. Up to 10 different fibres were measured and the contact angle was taken as the average value of them.

Surface free energy was calculated according to the method of Owens-Wendt [17]. The polar, $\gamma_{s}^{p}$, and dispersion, $\gamma_{s}^{d}$, contributions to the total surface free energy of the solid, $\gamma_{s}$, were calculated from the slope and intercept of Eq. (1):

$(1+\cos \theta) A=B \sqrt{\gamma_{s}^{p}}+\sqrt{\gamma_{s}^{d}}$ where:

$A=\frac{1}{2} \frac{\gamma_{L}}{\sqrt{\gamma_{L}^{d}}}$

$B=\sqrt{\frac{\gamma_{L}^{p}}{\gamma_{L}^{d}}}$

$\gamma_{L}, \gamma_{L}^{p}$ and $\gamma_{L}^{d}$ are the surface tension and the polar and dispersion contributions of the testing liquids. In the OwensWendt approximation, the solid surface tension is the sum of these two contributions.

\section{Results}

\subsection{SEM observation and chemical analysis}

The fibre morphology and surface texture, as revealed by SEM, do not change when calcinated fibres are subjected to activation treatments. A representative image of the 'as received', calcinated or activated glass fibres, irrespective of the activation treatment, is presented in Fig. 1. Long cylinders with smooth surfaces and average diameters of between 12 and $17 \mu \mathrm{m}$. are the common morphological characteristics of these fibres.

Silanizated fibres look very similar to activated fibres, but some differences can be observed as a consequence of the silanization treatment. For samples F-B-S, Fig. 2, where the silane covering degree is low, as will be shown below, an adherence following the mayor fibre axis can be observed. This protuberance resembles the trace that a debonded fibre may leave as a consequence of the silanization treatment. In the case of more extensively silanizated fibres, samples F-D-S, it is possible to find surface regions in which glass seems to be peeled from the bulk of the fibre, as shown in Fig. 3. It seems, therefore, that the fibres become bonded one to another when they are silanizated. For preparing the fibres for SEM inspection, the fibres may debond leaving the fibre trace, if the coating degree is low. If the coating degree is high then the adhesive joint strength becomes high enough to induce a peeling-out fracture mechanism. More work is being done for elucidating the exact origin of these SEM observations.

Table 2 shows the semi-quantitative chemical analysis of activated and silanizated fibres, expressed as atomic ratios between silicon and the other main elements: $\mathrm{Na}, \mathrm{Ca}$ and $\mathrm{Al}$ : boron was excluded from analysis because the instrument cannot detect it. Si has been selected as a reference element because its relative content does not change with any activation procedure.

It can be observed in Table 2 that the activation treatment by water reflux does not significantly change the glass composition, at least within the volume from which X-rays are emitted, which has been roughly estimated as $1 \mu \mathrm{m}^{3}$. For acidic activation treatments the content on $\mathrm{Al}, \mathrm{Ca}$, and $\mathrm{Na}$ 


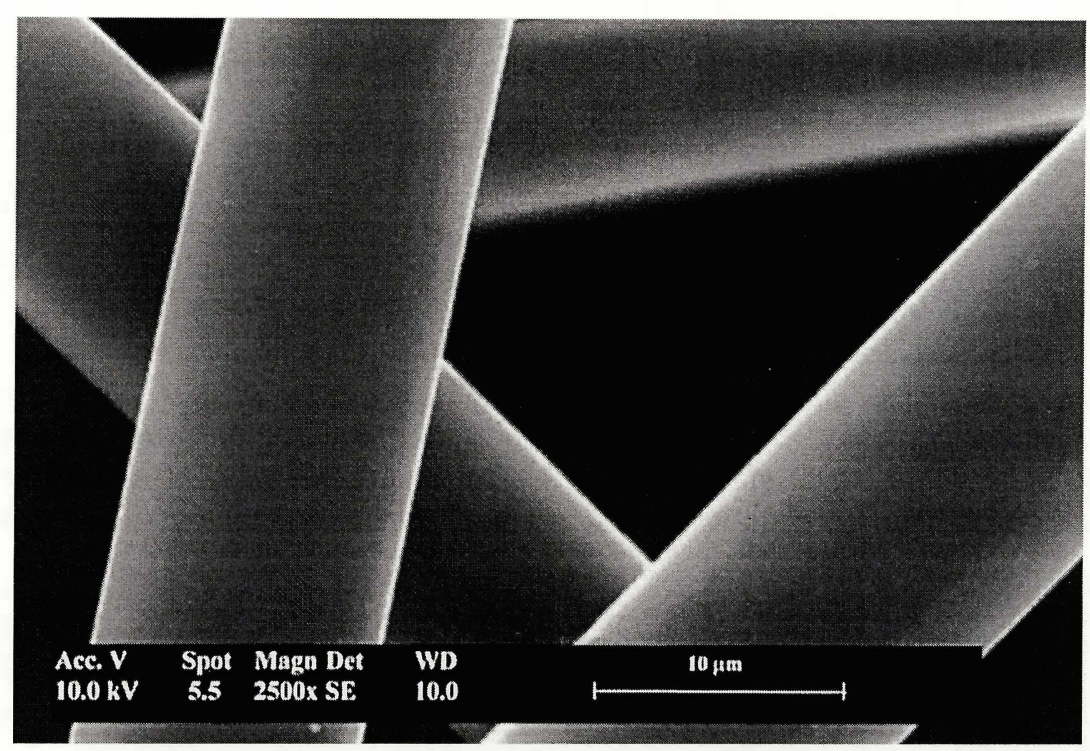

Fig. 1. SEM image of glass fibres activated with $\mathrm{HCl} 10 \%$ (w/w) for $3 \mathrm{~h}(\mathrm{~F}-\mathrm{D})$.

decreases and the effect is more pronounced for the highest activation time.

For silanizated samples, since the silanization time is low enough to alter the chemical composition within the measured volume, the content on $\mathrm{Al}, \mathrm{Ca}$ and $\mathrm{Na}$ should remain constant. A slight increase in $\mathrm{Si}$ content due to APES incorporation to the surface can be expected, increasing therefore the atomic ratios from Table 2. This effect is observed clearly only for sample F-D-S, suggesting that, for this sample, the polyorganosiloxane content is the greatest. Composition changes at the surface level cannot be observed with the analysis method employed, but its associated effects on fibres wettability will be studied below.

\subsection{FTIR spectra}

Fig. 4 shows two regions of the FTIR spectra of activated samples. Although the detailed assignment of the IR bands can be found in [14], the main IR observations can be summarized as follows. As can be observed at about $3425 \mathrm{~cm}^{-1}$ the tension band of bounded water increases in a parallel way as the intensity of activation treatments: none $<$ water $<\mathrm{HCl}(1 \mathrm{~h})<\mathrm{HCl}(3 \mathrm{~h})$. The free water band, which appears at $3250 \mathrm{~cm}^{-1}$, follows the same trend. The $\mathrm{O}-\mathrm{H}$ stretching band from silanol groups appears at $3650 \mathrm{~cm}^{-1}$ only for samples F-C and F-D. The position of the band suggests that the silanol groups are of intraglobular nature rather than surface groups [4].

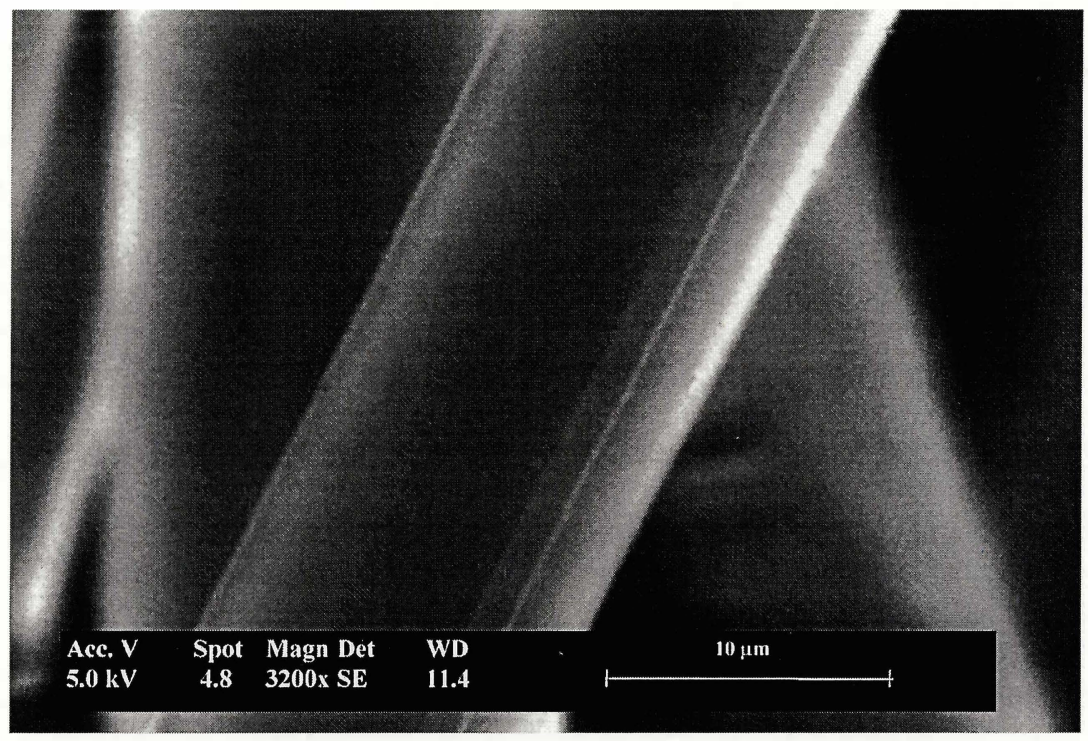

Fig. 2. SEM image of a silanizated glass fibre sample, activated previously with boiling water for $1 \mathrm{~h}$ (F-B-S). 


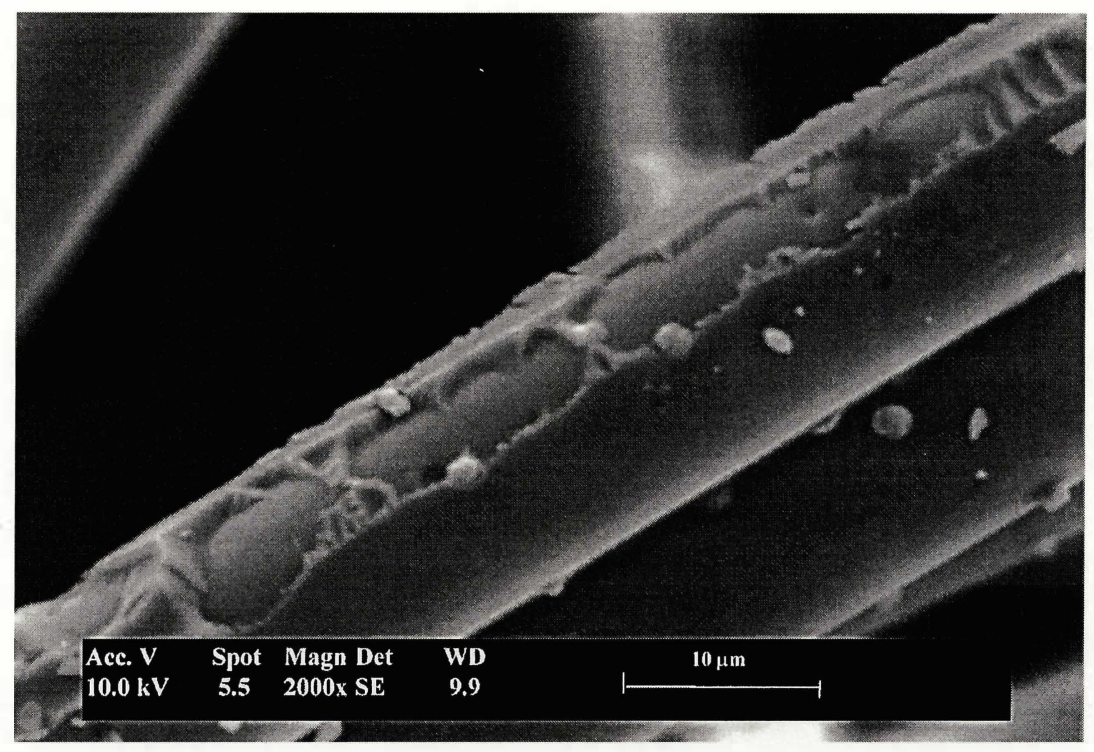

Fig. 3. SEM image of a silanizated glass fibre sample, activated previously with $\mathrm{HCl} 10 \%$ (F-D-S).

In the low energy region of the IR spectrum (Fig. 4(b)), acidic water bending bands can be observed at $1620 \mathrm{~cm}^{-1}$ only for samples activated with reflux of $\mathrm{HCl}(\mathrm{F}-\mathrm{C}$ and F-D). A progressive change of the band centered at $1000 \mathrm{~cm}^{-1}$ can be observed also. This band results from the contributions from $\mathrm{Si}-\mathrm{OH}, \mathrm{Si}-\mathrm{OSi}, \mathrm{Si}-\mathrm{OAl}$ and $\mathrm{Al}-\mathrm{OSi}$ stretching bands. Vibrations in which $\mathrm{Al}(\mathrm{III})$ is involved appear at $978 \mathrm{~cm}^{-1}$, and decrease as the intensity of the activation treatment increases; therefore, it can be concluded that $\mathrm{Al}(\mathrm{III})$ is leached out when activation takes place under acidic conditions. This result is in accordance with the chemical analysis results.

Fig. 5 shows the infrared spectra from silanizated glass fibres. In the high energy region of the spectra, the water signal is reduced, in comparison with Fig. 4, mainly for the F-A-S and F-B-S samples. The presence of residual silanol groups can be observed for F-C-S and F-D-S. The characteristic stretching bands from methyl and methylene groups can be observed between $2960-2850 \mathrm{~cm}^{-1}$ for all of the samples, being more intense for samples $\mathrm{F}-\mathrm{C}-\mathrm{S}$ and

Table 2

Atomic ratios between $\mathrm{Si}$ and the main constituent elements of E-glass fibres

\begin{tabular}{llll}
\hline Sample & Si/Al & Si/Ca & Si/Na \\
\hline F-A & $3.6 \pm 0.2$ & $3.1 \pm 0.2$ & $27 \pm 7$ \\
F-B & $3.7 \pm 0.5$ & $3.1 \pm 0.6$ & $32 \pm 7$ \\
F-C & $5.2 \pm 0.6$ & $5.1 \pm 0.7$ & $39 \pm 9$ \\
F-D & $8.3 \pm 0.6$ & $11 \pm 3$ & $60 \pm 13$ \\
F-A-S & $3.7 \pm 0.4$ & $3.0 \pm 0.3$ & $36 \pm 8$ \\
F-B-S & $3.8 \pm 1.1$ & $2.5 \pm 1.2$ & - \\
F-C-S & $5.7 \pm 0.8$ & $6.1 \pm 1$ & $56 \pm 17$ \\
F-D-S & $12 \pm 3$ & $17 \pm 7$ & - \\
\hline
\end{tabular}

F-D-S; this result suggests that the coating degree seems to be the highest for samples activated under acidic conditions at longer times.

Fig. 5(b) shows the low energy portion of the spectra. At about $1385 \mathrm{~cm}^{-1}$, bending bands of methylene groups can be observed clearly for sample F-D-S. The presence of these bands is due to either the propyl residues from APES or the uncondensed ethoxy residues: The latter can also be observed as indicated by a shoulder at about $900 \mathrm{~cm}^{-1}$.

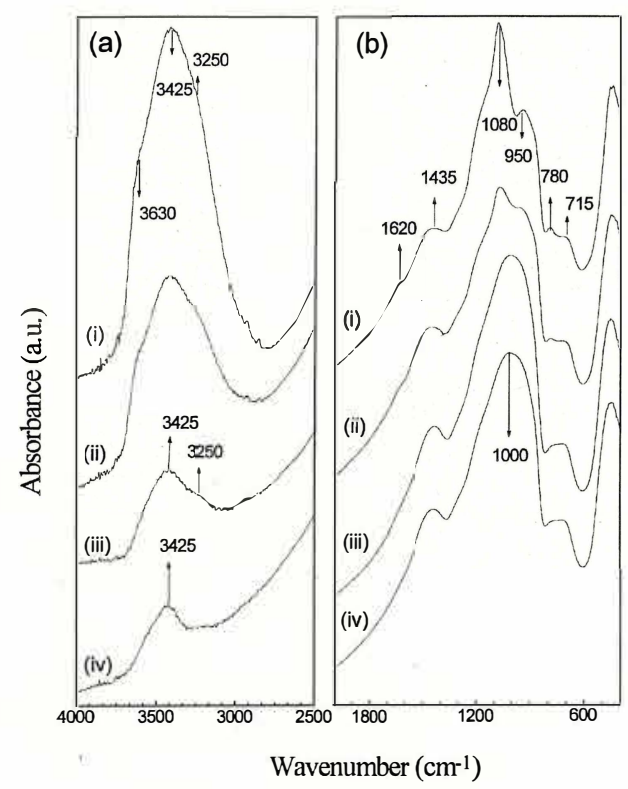

Fig. 4. Showing: (a) high and (b) low; energy regions of FTIR spectra from activated samples ((i): F-D; (ii): F-C; (iii): F-B; (iv): F-A). 


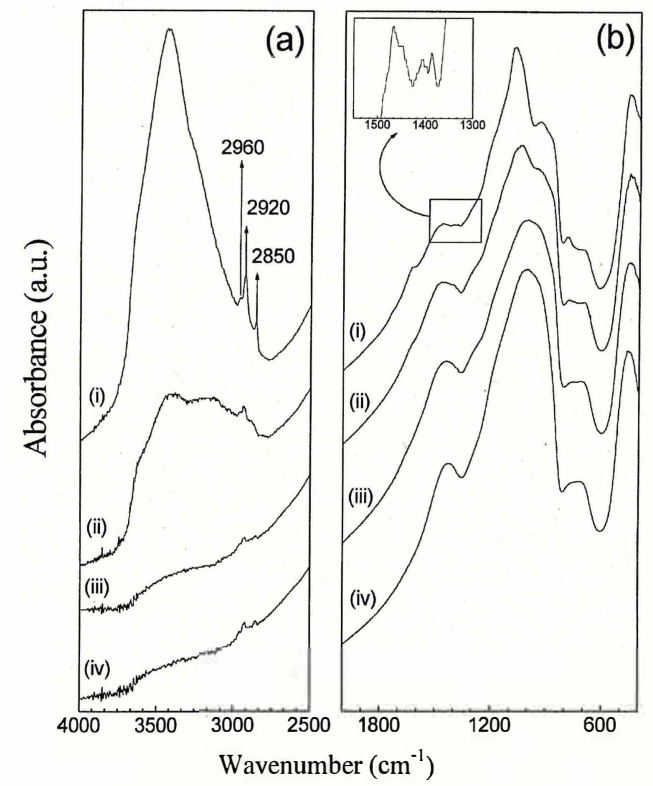

Fig. 5. Showing: (a) high and (b) low; energy regions of FTIR spectra from silanizated samples ((i): F-D-S; (ii): F-C-S; (iii): F-B-S; (iv): F-A-S).

\subsection{Dynamic contact angles}

In Table 3, the results from wettability studies are presented. The first column shows the difference between the advancing and receeding contact angles (hysteresis) for each sample when water is employed as the test liquid. Within the activated sample set (F-A to $\mathrm{F}-\mathrm{D}$ ), the hysteresis is minimum for the non-activated sample. It seems that the different activation treatments do not change the surface morphology very significatively, except for fibres activated with boiling water for $1 \mathrm{~h}$, for which the hysteresis is maximum.

For silanizated fibres, hysteresis is about $200 \%$ greater than for activated fibres, except for sample $\mathrm{F}-\mathrm{A}-\mathrm{S}$, where the hysteresis increases by about $400 \%$. That the hysteresis is higher for all the samples shows that the silanization process changes the surface structure. Some effects that may contribute to this change are [18]: the adsorption of water through the polyorgano-siloxane layer, surface roughness

Table 3

Hysteresis $\left(\left\langle\theta_{\mathrm{a}}\right\rangle-\left\langle\theta_{\mathrm{r}}\right\rangle\right)$ and surface free energy values

\begin{tabular}{llll}
\hline Sample & $\left\langle\theta_{\mathrm{a}}\right\rangle-\left\langle\theta_{\mathrm{r}}\right\rangle\left(^{\circ}\right)$ & \multicolumn{2}{l}{$\begin{array}{l}\text { Surface free energy (Owens-Wendt) } \\
\left(\mathrm{mN} \mathrm{m}^{-1}\right)\end{array}$} \\
\cline { 3 - 4 } & & $\gamma_{\mathrm{s}}^{\mathrm{p}}$ & $\gamma_{\mathrm{s}}{ }^{\mathrm{d}}$ \\
\hline $\mathrm{F}-\mathrm{H}$ & $9.2 \pm 3.2$ & $111.8 \pm 1.5$ & $0.2 \pm 0.01$ \\
$\mathrm{~F}-\mathrm{B}$ & $17.3 \pm 5.1$ & $98.5 \pm 3.1$ & $0.1 \pm 0.1$ \\
$\mathrm{~F}-\mathrm{C}$ & $11.4 \pm 4.1$ & $130.6 \pm 2.5$ & $2.2 \pm 0.4$ \\
$\mathrm{~F}-\mathrm{D}$ & $14.3 \pm 5.4$ & $138.9 \pm 5.5$ & $3.7 \pm 3.3$ \\
$\mathrm{~F}-\mathrm{A}-\mathrm{S}$ & $37.8 \pm 4.7$ & $5.0 \pm 0.5$ & $32.6 \pm 1.3$ \\
$\mathrm{~F}-\mathrm{B}-\mathrm{S}$ & $31.5 \pm 6.1$ & $8.3 \pm 1.2$ & $31.9 \pm 2.1$ \\
$\mathrm{~F}-\mathrm{C}-\mathrm{S}$ & $34.4 \pm 6.7$ & $3.2 \pm 0.6$ & $34.7 \pm 1.5$ \\
F-D-S & $35.6 \pm 4.1$ & $3.8 \pm 0.7$ & $32.2 \pm 1.8$ \\
\hline
\end{tabular}

and orientation of surface polar groups (amino-propyl residues). This result is also in agreement with the well known tendency of APES to polymerize, forming isolated islands or aggregates. Since SEM observations do not show any imperfection at 2000x magnification, it must be concluded that aggregates must have a characteristic length of less than $0.1 \mu \mathrm{m}$.

Activated fibres show a high surface free energy with a practically zero dispersion component. It is noteworthy that the F-B sample shows the lowest surface free energy, whereas acidic activation treatments lead to more hydrophilic surfaces, in agreement with a high silanol content as observed by FTIR.

Silanization with APES decreases the solid surface tension as compared with the untreated glass fibres. All of the samples show approximately the same value of the dispersion component, about $33 \mathrm{mNm}^{-1}$, which agrees with other reported values [7]. This component is the main contribution to the total solid surface free energy, showing the non-polar character of the coating. Slight differences can be found in the polar contribution, the highest value of which corresponds to the F-B-S sample; this result can be explained in terms of a partial coating of the fibre surface, which is in accordance with the low surface silanol concentration found for this sample. Samples C and D have about the same polar contribution, showing that the testing liquid interacts with the surface in the same way.

\section{Discussion}

Calcination of commercial fibres at $450^{\circ} \mathrm{C}$ to remove organic matter oxidizes the surface, creating a generally homogeneous layer of amorphous silica with a low surface silanol concentration. A higher surface free energy value with respect to the commercial fibres should be expected but not so high as that of the hydrated fibres, and this is observed in Table 3. Regeneration of silanol groups on silica is not an easy process [1] when neutral aqueous solutions are employed; accordingly, activation with boiling water for $1 \mathrm{~h}$ at least may hydrate the surface but without appreciable silanol regeneration. Although hydration is observed by an enhancement of the free water band at $3250 \mathrm{~cm}^{-1}$, a similar or slightly higher surface free energy value should be expected, but the values from Table 3 for samples F-A and $\mathrm{F}-\mathrm{B}$ show that this is not the case. It seems that hydration of calcinated fibres with boiling water and a subsequent drying process at $120^{\circ} \mathrm{C}$ reduces the surface free energy of the fibres. At the present moment the unique possible explanations can be associated to a surface dehydroxilation during the drying process, as well as to a selective leaching of boron oxide from the surface.

The acid activation of glass fibres greatly changes the surface composition and the hydration state of the glass. It seems that an acid media hydrolizes $\mathrm{Si}-\mathrm{O}$ and $\mathrm{Al}-\mathrm{O}$ bonds, allowing water diffusion through the bulk and generating a 
great number of silanol groups; some of them can be of an internal nature and, therefore, not accessible to APES, as the presence of residual silanol bands in the FTIR spectra of silanizated samples (F-D-S and F-C-S) reflect. The presence of acid water, that is to say, hydrogen bonded water, revealed by the IR band at $1620 \mathrm{~cm}^{-1}$, after drying at $120^{\circ} \mathrm{C}$ may confirm that a substantial amount of it is located inside the internal micropores of the fibre.

The greater amount of surface silanol groups for samples $\mathrm{C}$ and D may explain the higher silane content found for these samples, as revealed by their FTIR spectra. When the fibres are activated under less vigorous conditions the silane content is lower. In fact, the higher polar contributions to the total surface free energy of silanizated samples A and B is in accordance with a lower coating degree: amongst these two sample sets, the higher polar contribution corresponds to fibre activated with boiling water, suggesting a lower coating degree. This may be explained in terms of a lower number of surface silanol groups, which is in accordance with the low surface free energy value found for these samples.

\section{Conclusions}

Boiling water pretreatment at neutral $\mathrm{pH}$, does not increase the reactivity of glass fibres, with respect to simply calcinated fibres. Under acidic conditions, a great number of silanol groups are generated: although a substantial number of these silanols are of internal character, greater coating degrees can be achieved.

The different experimental techniques used in this work show that as a consequence of the different activation treatments, the silane coating degree increases in the following order: water activated $<$ non-activated $<$ acid treated for $1 \mathrm{~h}<$ acid treated for $3 \mathrm{~h}$.

Finally, SEM observations reveal that when the fibres are silanizated as fibre bundles and not as isolated filaments, the silane coating bonds the fibres one-to-another. If the coating degree is high enough, debonding may induce surface peeling on the fibres. This peeling mechanism should be investigated in more detail.

\section{Acknowledgements}

The authors wish to thank CICYT (MAT 930823) for financial support.

\section{References}

[1] R.K. Iler, The Chemistry of Silica Solubility, Polymerization, Colloid and Surface properties, and Biochemistry. Wiley, New York, 1979.

[2] K.L. Mittal, Silanes and other Coupling Agents, JSP, De. Utrech, 1992.

[3] E.P. Plueddemann, Silane Coupling Agents, Plenum Press, New York, 1982.

[4] P. Van Der Voort, I. Gillis-D́Hamers, K.C. Vrancken, E.F. Vansant, J. Chem. Soc., Faraday Trans. 87 (1991) 3899.

[5] K. Yoshinaga, H. Yoshida, Y. Yamamoto, K. Takakura, M. Komatsu, J. Colloid Inter. Sci. 153(1) (1992) 207.

[6] D. Gorshi, E. Klemm, P. Fink, H. Hörhold, J. Colloid Inter. Sci. 126(2) (1988) 445.

[7] L. Lee, J. Colloid Inter Sci. 27(4) (1968) 751.

[8] H. Ishida, J.L. Koenig, J. Colloid Inter. Sci. 64(3) (1978) 555.

[9] C. Chian, H. Ishida, J.L. Koenig, J. Colloid Inter. Sci. 74(2) (1980) 396.

[10] R.T. Graf, J.L. Koenig, H. Ishida, Anal. Chem. 56 (1984) 777.

[11] D. Wang, F.R. Jones, P. Denison, J. Mater. Sci. 27 (1992) 36.

[12] Y.C. Araujo, P.G. Toledo, V. Leon, H.Y. Gonzalez, J. Colloid Inter. Sci. 176 (1995) 485.

[13] A.A. Golb, A.I. Zubenco, B.V. Zhmud, J. Colloid Inter. Sci. 179 (1996) 482.

[14] J. González-Benito, J.C. Cabanelas, A.J. Aznar, M.R. Vigil, J. Bravo, J. Baselga, J. Appl. Polymer Sci. 62 (1996) 375.

[15] N. Suzuki, H. Ishida, Macromol. Symp. 108 (1996) 19.

[16] R.S.S. Murthy, D.E. Leyden, Anal. Chem. 58 (1986) 1228.

[17] D.K. Owens, R.C. Wendt, J. Appl. Polym. Sci. 13 (1969) 1741.

[18] J.D. Andrade, L.M. Smith, D.E. Gregoris, in: J.D. Andrade (Ed.), Surface and Interfacial Aspects of Biomedical Polymers, Plenum Press, New York, 1985. 